\section{Periodontitis in individuals with diabetes treated in the public health system of Belo Horizonte, Brazil}

\section{Periodontite em indivíduos com diabetes atendidos no sistema de saúde público de Belo Horizonte, Brasil}

\author{
Aline Mendes Silva \\ Andréa Maria Duarte Vargas \\ Efigênia Ferreira e Ferreira
}

Mauro Henrique Nogueira Guimarães de Abreu

Department of Social and Preventive Dentistry of the School of Dentistry of the Federal University of Minas Gerais, Belo Horizonte, Brazil.

Correspondence: Aline Mendes Silva. Rua Maria Heilbuth Surette, 528/102 - Buritis, Belo Horizonte, MG - Brazil CEP 30575-100. E-mail: mendes.silva.aline@gmail.com

\section{Abstract}

Objective: The aim of the present study was to investigate the prevalence of periodontitis among individuals with diabetes who use the public health system in the city of Belo Horizonte-Minas Gerais, Brazil, and the association of this condition with socioeconomic, behavioral and clinical variables. Methods: A cross-sectional study was carried out on a calculated sample of 300 individuals with diabetes. Periodontitis was defined as clinical attachment loss (CAL) $\geq$ $3 \mathrm{~mm}$ in two or more non-adjacent teeth or those that exhibited CAL $\geq 5 \mathrm{~mm}$ in $30.0 \%$ of teeth. All subjects were over 30 years of age and underwent a periodontal examination. Socioeconomic and behavioral characteristics as well as medical history and dental history were obtained from a structured interview. Multivariate analysis was conducted using Poisson regression. Results: Among the individuals with diabetes, 6.7\% exhibited good periodontal health, $68.0 \%$ exhibited gingivitis and $25.3 \%$ exhibited periodontitis. The following variables were associated with periodontitis after adjustment: male (PR 1.67 95\% CI 1.12, 2.49), individuals with diabetes for more than eight years (PR 1.63 95\% CI 1.63, 2.38), smokers (PR 1.71 95\% CI 1.10, 2.65); individuals with more than 12 missing teeth (PR 2.67 95\% CI $1.73,4.15)$ Conclusions: Multiple determinants are associated with the prevalence of periodontitis among patients with diabetes.

Keywords: Diabetes. Epidemiology. Dental health services. Periodontitis. 


\section{Resumo}

Objetivo: O objetivo do presente estudo foi investigar a prevalência de periodontite entre os indivíduos com diabetes que utilizam o sistema de saúde pública na cidade de Belo Horizonte, Minas Gerais, Brasil, e verificar a associação desta com condições socioeconômicas, comportamentais e variáveis clínicas. Métodos: Um estudo transversal foi realizado em uma amostra de 300 indivíduos com diabetes. Todos os indivíduos tinham mais de 30 anos de idade e foram submetidos a exame periodontal. Foi considerada periodontite os quadros de perda de inserção clínica (CAL) $\geq 3 \mathrm{~mm}$ em dois ou mais dentes não adjacentes ou os que apresentaram CAL $\geq 5 \mathrm{~mm}$ in $30.0 \%$ dos dentes. As características socioeconômicas e comportamentais, bem como a história médica e a história odontológica foram obtidas a partir de uma entrevista estruturada. Foi realizada uma análise multivariada utilizando-se a regressão de Poisson. Resultados: Entre os indivíduos com diabetes, $6,7 \%$ apresentaram boa saúde periodontal, $68,0 \%$ apresentaram gengivite e $25,3 \%$ apresentaram periodontite. As seguintes variáveis foram associadas com periodontite após o ajuste: sexo masculino (RP 1,67 95\% CI 1,12, 2,49), indivíduos com diabetes há mais de oito anos (RP 1,63 95\% CI 1,63, 2,38), tabagistas (RP 1,71 95\% CI 1,10; 2,65), indivíduos com mais de 12 dentes (RP 2,67 95\% CI 1,73, 4,15). Conclusões: Determinantes múltiplos estão associados à prevalência de periodontite em pacientes com diabetes.

Palavras-chave: Diabetes. Epidemiologia. Serviços de saúde bucal. Periodontite.

\section{Introduction}

Diabetes is an important public health problem, affecting 245 million people worldwide. Each year, seven million individuals develop diabetes and the projection for the year 2030 is that 366 million people will have the disease worldwide. Brazil has the sixth highest prevalence of diabetes in the world and the forecast for 2030 is that 11.3 million will be affected ${ }^{1}$.

Periodontitis is one of the main oral health problems ${ }^{2}$. The worldwide prevalence of periodontal disease is from 5 to $20 \%$ of the adult population ${ }^{3}$. In Brazil, the prevalence of severe periodontitis (periodontal pockets greater than $6 \mathrm{~mm}$ ) among individuals aged 35 to 44 and 65 to 74 years is $9.9 \%$ and $6.3 \%$, respectively ${ }^{4}$. The association between diabetes and periodontal diseases has been recognized in the dental literature for many years ${ }^{5}$. Periodontitis is considered one of the main oral health problems encountered in patients with diabetes ${ }^{6}$. With the increase in the incidence of diabetes worldwide, its negative impact on oral health should be considered $^{2}$. Scientific evidence has shown for some time that diabetes is a risk factor for the development of periodontitis. More recent studies have shown that periodontal diseases can have a negative effect on patient control in diabetes ${ }^{7}$. Evidence of this association supports the concept of increased severity, but not the extent of periodontitis in subjects with poorly controlled diabetes $^{8}$. Therefore, the maintenance of periodontal health may result in improved control of blood sugar levels among such individuals ${ }^{7}$. Recent revisions confirm that Type 2 diabetes can be considered a risk factor for periodontitis ${ }^{9}$ and suggest that periodontal treatment could improve the control of glucose levels ${ }^{10}$.

Despite advances in recent years, the public healthcare system in Brazil offers limited access to dental services. This problem is also perceived in relation to individuals with diabetes, the treatment of whom is not prioritized by the system ${ }^{11}$. The aim of the present study was to investigate the 
prevalence of periodontal diseases among individuals with type I and type II diabetes who use the public health system in the city of Belo Horizonte (Brazil) and evaluate the association of this condition with socioeconomic, behavioral, and clinical variables, as well as with dental care offered at public health facilities in the city of Belo Horizonte (Minas Gerais, Brazil).

\section{Methods}

The present study was carried out from April to June 2006 in the city of Belo Horizonte, the state capital of Minas Gerais, Brazil. According to information made available by City Hall, healthcare services are organized into nine public health districts. Oral healthcare in the Brazilian public healthcare system of Belo Horizonte is structured in the following manner: Basic care, with 200 oral health teams; specialized care, with 46 specialist surgeon dentists, including five in the field of periodontics; and tertiary care, performed in a hospital setting. The study was approved by the Research Ethics Committee of the Federal University of Minas Gerais (Protocol 012/2004).

For the calculation of the study population, a proportion estimate was performed for the occurrence of the disease using the formula established by the $\mathrm{WHO}^{12}$. A $75.0 \%$ prevalence of periodontal disease (q) in individuals with diabetes was considered ${ }^{13}$, with a required precision of $95.0 \%(1-\alpha)$ and a $4.8 \%$ level of precision (d).

The sample was calculated as a total of 300 dentulous male and female individuals over 30 years of age. Belo Horizonte has nine health districts, which have differences in the number of patients with type I and II diabetes. Stratified random sampling was performed for each district. Thus, the number of randomly selected patients was proportional to the number of individuals with diabetes in each district. No patient refused to participate in our study. Type I diabetes was determined in individuals with a previous medical diagnosis of betacell destruction, usually leading to absolute insulin deficiency. Type 2 diabetes was determined in individuals with previous medical diagnosis of diabetes ranging from predominantly insulin resistance with relative insulin deficiency to predominantly an insulin secretory defect with insulin resistance $^{14}$. Table 1 displays the distribution of patients with diabetes in the Brazilian public healthcare system in nine health districts of the city of Belo Horizonte in 2003.

Clinical examinations were performed by a single examiner in the dental offices of the selected healthcare units, using a reflector for illumination and a triple

Table 1 - Number of patients with diabetes and distribution in the Brazilian public healthcare system, in nine health districts Belo Horizonte, 2003.

Tabela 1 - Número de indivíduos com diabetes e distribuição nos nove distritos sanitários do Sistema Único de Saúde de Belo Horizonte, 2003.

\begin{tabular}{lcc}
\hline Health Discricts & Belo Horizonte & Sample (\%) \\
\hline Barreiro & 10,301 & $33(11.0 \%)$ \\
Centro-Sul & 5,900 & $19(6.3 \%)$ \\
Leste & 9,926 & $32(10.6 \%)$ \\
Nordeste & 17.138 & $55(18.3 \%)$ \\
Noroeste & 16,482 & $53(17.6 \%)$ \\
Norte & 10,301 & $33(11.0 \%)$ \\
Oeste & 9,927 & $32(10.6 \%)$ \\
Pampulha & 5,244 & $16(5.6 \%)$ \\
Venda Nova & 8,428 & $27(9.0 \%)$ \\
\hline Total & 93,647 & $300(100 \%)$ \\
\hline
\end{tabular}


syringe to dry teeth. Biosafety norms were followed. Williams (Hu-Friedy®, Chicago, USA) periodontal probes, mouth mirrors and gauze were used. All faces of the teeth were examined and data were recorded on an odontogram. Probing was performed in a circumferential manner and the highest values found in the sites were annotated. In order to avoid errors inherent to the probing process, the option made was to exclude third molars. The Kappa agreement index $(\mathrm{K})$ was used and revealed satisfactory values for probing depth (0.81), clinical attachment loss (0.91), and bleeding upon probing $(0.79)$ for a single examiner ${ }^{12}$.

Interviews were also conducted to collect data on dental care (dental care in the previous year, visit to the dentist's office in the previous year), medical history (type, duration, control of diabetes), socioeconomic data (age, gender, income, schooling, marital status), and behavioral data (tobacco smoking habits). The following parameters were considered in the diagnosis: gingivitis, individuals who exhibited at least one site of bleeding on probing based on the criteria of the American Academy of Periodontology (2000) ${ }^{15}$; and periodontitis, individuals who exhibited clinical attachment loss (CAL) $3 \mathrm{~mm}$ in two or more nonadjacent teeth or those who exhibited CAL $5 \mathrm{~mm}$ in $30.0 \%$ of teeth based on the criteria proposed by Tonetti \& Claffey $(2005)^{16}$.

The results were entered in a database using the Statistical Package for Social Science (SPSS, Chicago, USA, version 17.0). Descriptive analysis of the data was based on the calculation of proportions for the following variables: prevalence of periodontitis, dental care in the previous year, medical history, socioeconomic and behavioral data. Univariate analysis was performed and the dependent variable was dichotomized into the presence or absence of periodontitis. The chi-square test $\left(\mathrm{x}^{2}\right)$ was used in this step, with the level of statistical significance set at $=0.05$. The variables income, age, duration of diabetes, and number of missing teeth were dichotomized using the median value. Schooling was dichotomized by grouping education levels: "university/high school" and "elementary/ no schooling". For the identification of the factors associated with the prevalence of periodontitis a multivariable analysis was performed using the Poisson regression analysis with binary outcomes allowing the estimation of the prevalence ratios (PR) and their $95 \%$ confidence intervals. The variables with $\mathrm{p}$ values $\leq 0.20$ in the univariate analysis were included in the multivariable analysis and were kept in the model if they remained statistically significant $(\mathrm{p}<0.05)$.

\section{Results}

The average age of the study population was 55.3 years $( \pm 10.0)$, with a median age of 55 years. Average duration of diabetes was 9.1 years $( \pm 7.2)$. The sample was comprised mostly of women $(60.0 \%)$. Average monthly family income was US\$229 ( \pm \$255); $70.7 \%$ earned up to US $\$ 233$ (exchange rate: US $\$ 1.00=\mathrm{R} \$ 2.57$ in April 2005). A total of $84.0 \%$ of participants had either no schooling or only elementary education; $15.3 \%$ of the patients were tobacco smokers; $28.7 \%$ had type I diabetes and $71.3 \%$ had type II diabetes. The mean number of missing teeth was $13.49( \pm 7.0) ; 51.0 \%$ of participants had lost as many as 12 teeth.

A total of $6.7 \%$ exhibited a healthy periodontium; $68.0 \%$ exhibited gingivitis; and $25.3 \%$ exhibited periodontitis. The univariate analysis revealed that periodontitis was statistically more prevalent among men ( $\mathrm{p}$ $=0.001$ ); among participants with type II diabetes $(\mathrm{p}=0.030)$; those with more than eight years of diabetes $(p=0.027)$; those who had lost more than 12 teeth $(\mathrm{p}=0.000)$; those with tobacco smoking habits ( $\mathrm{p}=0.019)$; and those who had not visited the dentist in the previous year $(p=0.016)$. Table 2 displays the results of the univariate analysis.

The multivariate analysis (Table 3 ) revealed that the following variables maintained a statistical association with the prevalence of periodontitis among participants: gender, duration of diabetes, tobacco smoking habits, number of missing teeth. The prevalen- 
Table 2 - Univariate analysis of the distribution of the independent variables and prevalence of periodontitis, Brazil, 2006.

Tabela 2 - Análise univariada da distribuição das variáveis independentes e prevalência de periodontite, Brasil, 2006.

\begin{tabular}{|c|c|c|c|c|c|}
\hline \multirow{2}{*}{$\begin{array}{l}\text { Variable } \\
\text { Gender }\end{array}$} & \multicolumn{2}{|c|}{$\begin{array}{c}\text { Absence of } \\
\text { periodontitis }\end{array}$} & \multicolumn{2}{|c|}{$\begin{array}{l}\text { Presence of } \\
\text { periodontitis }\end{array}$} & \multirow[t]{2}{*}{$p$-value } \\
\hline & $\mathrm{N}$ & $\%$ & $\mathrm{~N}$ & $\%$ & \\
\hline Female & 147 & 81.7 & 33 & 18.3 & 0.001 \\
\hline Male & 77 & 64.2 & 43 & 35.8 & \\
\hline \multicolumn{6}{|l|}{ Age (years) } \\
\hline $30-54$ & 116 & 78.4 & 32 & 21.6 & 0.145 \\
\hline $55-86$ & 108 & 71.1 & 44 & 28.9 & \\
\hline \multicolumn{6}{|l|}{ Income } \\
\hline Up to US\$ 175 & 102 & 71.8 & 40 & 28.2 & 0.308 \\
\hline Above US\$ 175 & 111 & 77.1 & 33 & 22.9 & \\
\hline \multicolumn{6}{|l|}{ Schooling } \\
\hline No schooling & 17 & 60.7 & 11 & 39.3 & 0.054 \\
\hline Up to 8 years & 165 & 74.0 & 58 & 26.0 & \\
\hline Over 8 years & 41 & 85.4 & 7 & 14.6 & \\
\hline \multicolumn{6}{|l|}{ Marital status } \\
\hline Married, co-habitation & 131 & 76.2 & 41 & 23.8 & 0.490 \\
\hline Single, divorced, widowed & 93 & 72.7 & 35 & 27.3 & \\
\hline \multicolumn{6}{|l|}{ Type of diabetes } \\
\hline Type I & 57 & 66.3 & 29 & 33.7 & 0.030 \\
\hline Type II & 166 & 78.3 & 46 & 21.7 & \\
\hline \multicolumn{6}{|l|}{ Duration of diabetes } \\
\hline Up to 8 years & 120 & 80.0 & 30 & 20.0 & 0.027 \\
\hline Over 8 years & 99 & 68.8 & 45 & 31.2 & \\
\hline \multicolumn{6}{|c|}{ Report of controlled glucose } \\
\hline Yes & 91 & 79.8 & 23 & 20.2 & 0.221 \\
\hline No & 113 & 73.4 & 41 & 26.6 & \\
\hline \multicolumn{6}{|l|}{ Tobacco Smoking Habits } \\
\hline Yes & 18 & 39.1 & 28 & 60.9 & 0.019 \\
\hline No & 196 & 77.2 & 58 & 22.8 & \\
\hline \multicolumn{6}{|l|}{ Missing teeth } \\
\hline Up to 12 & 132 & 86.3 & 21 & 13.7 & 0.000 \\
\hline More than 12 & 92 & 62.6 & 55 & 37.4 & \\
\hline \multicolumn{6}{|l|}{ Dental care in previous year } \\
\hline Yes & 95 & 82.6 & 20 & 17.4 & 0.016 \\
\hline No & 127 & 70.2 & 54 & 29.8 & \\
\hline
\end{tabular}

a - $p$-value according to Pearson's chi-square test / a - valor $p$ Segundo o teste qui-quadrado de Pearson 
Table 3 - Multivariate analysis of the distribution of the independent variables and prevalence of periodontitis, Brazil, 2006.

Table 3 - Análise multivariada da distribuição das variáveis independentes e prevalência de periodontite, Brasil, 2006.

\begin{tabular}{lccc}
\hline Variable & PR & Cl (95\%) & p-value \\
\hline Gender & 1.00 & & 0.011 \\
Female & 1.67 & $1.12-2.49$ & \\
Male & & & \\
Duration of diabetes & 1.00 & $1.12-2.38$ & \\
Up to 8 years & 1.63 & & \\
More than 8 years & & & \\
Tobacco smoking habits & 1.00 & $1.10-2.65$ & \\
No & 1.71 & & \\
Yes & & & 0.000 \\
Missing teeth & 1.00 & $1.73-4.15$ & \\
Up to 12 & 2.67 & \\
More than 12 &
\end{tabular}

ce ratio (PR) for periodontal disease was 1.67 (95\% confidence interval [CI]: 1.12, 2.49) among men; 1.63 (95\% CI: 1.63, 2.38) for individuals with diabetes for more than eight years; 1.71 (95\% CI: 1.10, 2.65) for smokers; 2.67 (95\% CI: 1.73, 4.15) for individuals with more than 12 missing teeth.

\section{Discussion}

Periodontitis is the second largest health problem ${ }^{17}$ and advanced periodontal disease affects 10 to $15 \%$ of the population worldwide $^{18}$. In Brazil, the prevalence of individuals with periodontal pockets deeper than $4 \mathrm{~mm}$ is $9.9 \%$ in the population between 35 and 44 years of age, and $6.3 \%$ among individuals 65 to 74 years of age ${ }^{4}$. In the present study, there was a $25.3 \%$ prevalence of periodontitis among individuals with diabetes. As the national data cited above refer to a population without diabetes, the results of this study demonstrate that diabetic individuals have a higher prevalence of periodontal disease than individuals without diabetes ${ }^{18,19}$.

Recognition of the mounting evidence on the relationship between oral and systemic health ${ }^{9,10,20}$ will confront dental hygienists, dentists, physicians, nurses, and other healthcare workers with the importance of working together. Nowhere is this more important than in the early identification of individuals with undiagnosed diabetes and the co-management of oral and overall health in patients with diabetes. There is sufficient evidence of the bidirectional relationship between diabetes and periodontal disease to formulate guidelines for screening undiagnosed diabetes and the co-management of patients with diabetes in the clinical practice of dentistry and dental hygiene. There is also sufficient evidence regarding the role periodontal disease plays in increasing systemic inflammation to suggest that non-dental healthcare providers should screen patients for periodontal disease. For dental and non-dental practitioners who embrace the opportunity to become more actively involved in this important arena of healthcare, this new and exciting level of clinical practice is certain to benefit patients and be professionally rewarding ${ }^{21}$.

In a population of diabetic individuals in a public hospital, Drumond-Santana et al. (2007) found a $49.1 \%$ prevalence of periodontitis, which is higher than the value found in the present study ${ }^{19}$. However, two aspects may explain this difference. Firstly, the sample assessed was restricted to a general hospital, which may reflect a lesser proximity to the actual situation of perio- 
dontal health of the diabetic population. Secondly, the criterion used for the diagnosis of periodontitis was the presence of one site with a depth of $>4 \mathrm{~mm}^{13}$. Considering this same cutoff point, the prevalence of periodontitis in diabetic individuals in the present study would be $74.0 \%$. Other studies have mentioned that individuals with diabetes have higher percentages of deep pockets and severe attachment loss than non-diabetic individuals and individuals with diabetes have a three-fold greater chance of suffering the loss of periodontal support tissue ${ }^{18}$.

In the present study, there was a statistically significant association between periodontitis and gender $(\mathrm{p}=0.011)$. This corroborates other studies reporting that periodontal problems are more prevalent and more severe among diabetic men ${ }^{22}$. Such a finding implies that public healthcare services need to actively seek changes in clinic hours and other measures that address care for men with diabetes, as males seek health services less often than women ${ }^{23}$.

There was a statistically significant association between the time from which the patient was diagnosed with diabetes and the presence of periodontitis $(p=0.011)$. Some studies have found a relationship between the duration of diabetes and periodontal conditions, whereas others have reported no differences when comparing the duration of diabetes with the periodontal parameters of bleeding, probing depth, and clinical attachment loss ${ }^{24}$.

According to the World Health Organization $(2007)^{3}$, tobacco smoking is a risk factor for the development of periodontal disease. In the present study, tobacco smoking was associated with periodontitis $(\mathrm{p}=0.016)$. This finding corroborates studies that have found that tobacco modifies clinical gingival characteristics and is considered a risk factor for periodontal disease $\mathrm{e}^{14}$. It has also been reported that individuals with diabetes who smoke are 1.71 times more likely to exhibit periodontal disease than those who do not smoke ${ }^{19}$.
Tooth loss was associated with periodontitis ( $p=0.000)$. There was an average of 13.4 missing teeth in the present study. It is important to remember that tooth loss is also quite high among the general Brazilian population, with an average of 13.2 missing teeth among 35-to-44-year-olds and 25.8 among 65-to-74-year-olds ${ }^{4}$. Diabetes may be considered an indicator of the risk for tooth loss ${ }^{24}$.

Stratified random sampling was performed in the present study. No weighing of the estimated prevalence ratio values was carried out in the analysis. So this is a limitation of our results.

Dental care for individuals with diabetes is deficient in Brazil, as access to dental services in the country is limited to a portion of the population ${ }^{9}$ and there are no priorities for any special groups, except pregnant women and children under 14 years of age. Data from a national epidemiological survey (SB-BRASIL) carried out in 2004 reveal that $2.82 \%$ of the population between 35 and 44 years of age and $5.81 \%$ of those in the 65-to74-year-old age group had never been to the dentist. It is estimated that 30 million Brazilians have never been to a dental office, despite the fact that the country has one of the highest numbers of dentists in the world ${ }^{4}$. The Brazilian public healthcare system is an organization of considerable importance from the standpoint of access to dental services, but still plays a proportionately small role when considering the oral health needs of the Brazilian population.

\section{Conclusion}

The results of the present study indicate a high prevalence of gingivitis $(68.0 \%)$ and periodontitis (25.3\%) among individuals with diabetes who utilize public health services in the city of Belo Horizonte (Brazil). This prevalence was much higher than that found in the Brazilian population without diabetes as well as higher than the one found in other studies investigating the prevalence of periodontitis in diabetic populations. Multiple determinants, such as 
clinical and behavioral factors, are associated to the prevalence of periodontitis among patients with diabetes. Public healthcare strategies are needed in order to broaden access to oral health care services in Brazil and to integrate healthcare professionals regarding care for individuals with diabetes.

\section{References}

1. Wild S, Roglic G, Green A, Sicree R, King, H. Global prevalence of diabetes: estimates for the year 2000 and projections for 2030. Diabetes Care 2004; 27: 1047-53.

2. World Health Organization. Strengthening the Prevention of periodontal disease: the WHO approach. $J$ Periodontol 2005; 76: 2187-93.

3. World Health Organization. Oral Health Facts. Available from http://www.who.int/ mediacentre/factsheets/ fs318/en/index.html. [Acessed 10 July 2009].

4. Brazil. Project SB Brazil 2003: oral health conditions of Brazilian population 2002-2003. Main Results. Brasília: Distrito Federal; 2004.

5. Taylor G. Bi-directional interrelationships between diabetes and periodontal diseases: an epidemiologic perspective. Ann Periodontol 2001; 6: 99 -112.

6. Guneri P, Unlu F, Yesilbek B, Bayraktar F, Kokuludag A, Hekimgil M et al. Vascular endothelial growth factor in gingival tissues and crevicular fluids of diabetic and healthy periodontal patients. J Periodontol 2004; 75: 91 7 .

7. Herring ME, Shah SK. Periodontal Disease and Control of Diabetes Mellitus. J Am Osteopath Assoc 2006; 106: 416-21.

8. Kinane D, Bouchard P; Group of European Workshop on Periodontology. Periodontal diseases and health: Consensus Report of the Sixth European Workshop on Periodontology. Consensus Report. J Clin Periodontol 2008; 35(S8): 333-37.

9. Chávarry NG, Vettore MV, Sansone C, Sheiham A. The relationship between diabetes mellitus and destructive periodontal disease: a meta-analysis. Oral Health Prev Dent 2009; 7: 107-27.

10. Garcia R. Periodontal treatment could improve glycaemic control in diabetic patients. Evid Based Dent 2009; 10: 20-1.

11. Fernandes LS, Peres MA. Association between primary dental care and municipal socioeconomic indicators. Rev Saúde Publica 2005; 39(6): 930-6.

12. World Health Organization. Oral Health Surveys. Basic Methods, 4th ed. Geneva; 1997.

13. Sonis ST, Fazio RC, Fang LF. Principles and practice of oral medicine. Philadelphia: WB Saunders Company; 1995.
14. American Diabetes Association (ADA). Diagnosis and Classification of Diabetes Mellitus. Diabetes Care 2009; 32(1): $62-7$.

15. American Academy of Periodontology (AAP). Parameters of care. J Periodontol 2000; 71(S5): 847-83.

16. Tonetti MS, Claffey N. Advances in the progression of periodontitis and proposal of definitions of a periodontitis case and disease progression for use in risk factor research: Group C Consensus report of the 5th European workshop in periodontology. J Clin Periodontol 2005; 32(S6): 210-3.

17. Petersen PE. The world oral health report $2003-$ continuous improvement of oral health in the 21st century - the approach of the WHO Global Oral Health Programme. Community Dent Oral Epidemiol 2003; 31(S1): 3-24.

18. Lindhe J. Epidemiology of periodontal diseases (in Portuguese). In: Clinical periodontology and implant dentistry. Rio de Janeiro: Guanabara-Koogan; 2005. p. 47-80.

19. Drumond-Santana T, Costa FO, Zenóbio EG, Soares RV. Impact of periodontal disease on quality of life for dentate diabetics. Cad Saúde Pública 2007; 23: 637-44.

20. Taylor GW, Borgnakke WS. Periodontal disease: associations with diabetes, glycemic control and complications. Oral Dis 2008; 14: 191-203.

21. Hein C. Scottsdale revisited: the role of dental practitioners in screening for undiagnosed diabetes and the medical co-management of patients with diabetes or those at risk for diabetes. Compend Contin Educ Dent 2008; 29: 538-40.

22. Maia FR, Silva AAR, Carvalho QRM. Proposta de um protocolo para o atendimento odontológico do paciente diabético na atenção básica. Rev Espaço para a Saude 2005; 7: 6-29.

23. Travassos C, Viacava F, Pinheiro R, Brito A. Utilization of health care services in Brazil: gender, family characteristics, and social status. Pan American J Public Health 2002; 11: 365-73.

24. Lagervall M, Jansson L. Relationship between tooth loss/ probing depth and systemic disorders in periodontal patients. Swed Dent J 2007; 31: 1-9.

Recebido em: 13/09/09

Versão final reapresentada em: 07/02/10 Aprovado em: 11/02/10 